\title{
Digital cartographic support of geodynamic safety of subsoil use based on UAV technologies
}

\author{
Aleksandr Solovitskiy ${ }^{1, *}$ \\ ${ }^{1}$ Kemerovo State University, 6, Krasnaya Street, 650000, Kemerovo, Russia
}

\begin{abstract}
It is established that the problem of digital cartographic support for geodynamic safety based on UAV technologies is the following: on the one hand, a significant increase in accuracy and efficiency of survey work and on the other hand - the lack of new models for approximating the crustal blocks, taking into account the adequacy of their configuration, hierarchy, structure, interaction and geodynamic activity. Traditional technologies are focused on the use of flat models of crustal blocks, which are not adequate and give ambiguous state parameters. The aim of the research is to develop a theory of digital cartographic support for the geodynamic safety of subsurface use, which provides not only the creation of new models of blocks of the earth's crust based on their selection and identification, taking into account the accuracy of cartographic materials, but also provides an information basis for gaining new knowledge about their stress-strain state according to the structure hierarchy which is necessary to solve this problem. Based on the performed research, it was found that the morphostructural analysis of the cartographic materials of the territory in the area of the mining enterprise, obtained on the basis of UAV technologies, is more informative and automated, covers the latest period up to one million years and takes into account the dependence of their errors on the duration and relaxation of geodynamic processes. The practical use of this theory is safe subsoil use.
\end{abstract}

\section{Introduction}

In the mining industry, UAV technology is used primarily as a measurement tool for underground and geodetic surveying. However, their capabilities are much broader than the mapping of the territories of mining enterprises. Their use implements modern trends to improve the accuracy, efficiency and automation of processes, both in the making of measurements and in the processing of the information received. Therefore, they are in demand for the study of natural and man-made geodynamic processes in the development of coal deposits, which is of great scientific and practical importance $[1,2,3,4,5,6]$. Information about these processes is crucial in terms of forecasting catastrophic geodynamic phenomena (GDP): rock bursts, sudden outbursts, earthquakes $[7,8,9,10,11,12,13,14$, 15]. The theory of digital cartographic support for geodynamic security based on UAV technologies has not been developed yet $[1,2,3,4,5,6]$. Traditional technologies of underground and geodetic surveying in areas of development of coal deposits are currently

${ }^{*}$ Corresponding author: san.mdig@mail.ru 
focused on mapping and studying the kinematics of the earth's crust. The development of the theory of digital cartographic support for geodynamic safety based on UAV technologies in areas of development of coal deposits is hampered by the lack of new mathematical models for approximating blocks of the earth's crust to ensure the adequacy of their configuration, hierarchy, interaction and geodynamic activity $[9,16]$. The main condition for such models is the isolation and identification of crustal blocks. The purpose of this theory is the collection, storage, processing and analysis of information on the isolation and identification of the boundaries of crustal blocks in areas of development of coal deposits, which is the basis for assessing the possible risk of GDP manifestations. Only in this way will the obtained results provide an information basis for obtaining new knowledge about the stress-strain state of crustal blocks of various ranks in the development of coal deposits, which will not only solve the problem of geodynamic safety, but also national economic problems. The presented above allows us to consider it relevant to the development of the theory and methods of the theory of digital cartographic support for geodynamic security based on UAV technologies. The practical use of its results is to ensure the creation of a local monitoring for assessing the geodynamic hazard during the development of coal deposits.

First of all, we will consider the role of terrain information obtained using remote sensing methods, including UAV technology. It is known that modern relief was formed in modern times, therefore, as a methodological basis for geodynamic safety, it is impossible not to take into account the hypothesis of the action and relaxation of stresses [16]. It is known that the stress relaxation period $(\tau)$ for the Earth's crust as a whole can be estimated by the ratio:

$$
\tau=\eta / \mu,
$$

where $\eta$ - effective viscosity; $\mu$ - hardness modulus.

At $\eta=10^{24} \mathrm{~Pa} \mathrm{~s}$ and $\mu=3 * 10^{5} \mathrm{MPa}$ stress relaxation period is $1 * 10^{6}$ years. Consequently, a method is needed to study the nature of geodynamic processes that took place in the area of a field development at least one million years ago. This method is a morphostructural analysis. In this method, the interaction of the crustal blocks and the evaluation of their deformations in the study area is a desktop study based on cartographic information. However, the results of the evaluation of the relaxation time of the deformations of the crustal blocks (during their interaction), depending on the cartographic material used, are not defined in the traditional technology. The authors propose the following methodology. It is known that the error in determining the marks for cartographic materials does not exceed $1 / 3$ of the height of the contour interval. Knowing the average velocities of vertical movements $V$, let us estimate the period $T$, or which the altitude changes due to geodynamic processes do not exceed the error $m_{\mu}$ of the definitions of elevations (Table 1). The above dependence will be presented in the following form:

$$
T=m_{H} / V \text {. }
$$

The results shown in Table 1 show that the information on geodynamic processes, reflected in a large-scale series of paper maps, makes it possible to estimate their significant periods of time, ranking them by age. As for taking into account the errors of this series of maps, then, if the action of stresses ceased 1 million years ago, then 333333 years before the period under study, these stresses relax by $71 \%$ (Table 1). The digital mapping technology and electronic maps obtained on the basis of the UAV - technology, where information errors depend on the resolution of the devices (in the case under study, 1200 pixels per inch) (Table 2) are of undoubted interest. Using the digital representation of cartographic information is more preferable, since in this case, for 208 thousand years, $18 \%$ of the existing stresses will not relax. 
Table 1. The period of time for which the changes in heights due to geodynamic processes do not exceed the errors of their definition (traditional paper technology).

\begin{tabular}{|c|c|c|c|}
\hline \multirow{2}{*}{$\begin{array}{c}\text { Topographic map } \\
\text { scales }\end{array}$} & \multirow{2}{*}{$\begin{array}{c}\text { Height of contour } \\
\text { interval, } \mathbf{~ m}\end{array}$} & \multicolumn{2}{|c|}{$\begin{array}{c}\text { Time period } \boldsymbol{T} \text { (year) with speed of vertical } \\
\text { movements } \boldsymbol{V}\end{array}$} \\
\cline { 3 - 4 } & & $\mathbf{V = 0 . 1} \mathbf{~ m m} /$ year & $\boldsymbol{V}=\mathbf{0 . 0 1} \mathbf{~ m m} / \mathbf{y e a r}$ \\
\hline $1: 1000000$ & 100 & 333333 & 3333333 \\
\hline $1: 500000$ & 50 & 166667 & 1666667 \\
\hline $1: 100000$ & 20 & 66667 & 666667 \\
\hline $1: 50000$ & 10 & 33333 & 333333 \\
\hline $1: 25000$ & 5 & 16667 & 166667 \\
\hline $1: 10000$ & 2.5 & 8333 & 83333 \\
\hline $1: 5000$ & 2 & 6667 & 66667 \\
\hline $1: 2000$ & 1 & 3333 & 33333 \\
\hline $1: 1000$ & 0.5 & 1667 & 16667 \\
\hline $1: 500$ & 0.25 & 834 & 8334 \\
\hline
\end{tabular}

In the absence of severity in the relief of the boundaries of the crustal blocks, the use of geophysical maps, in the opinion of the authors, is of considerable interest. For gravimetric maps, information errors are estimated by the total interpolation errors $\mathrm{m}_{\Delta \mathrm{g}}$. The time period $T$, (Tables 3 and 4), for which the changes in gravity due to geodynamic processes do not exceed $\mathrm{m}_{\Delta \mathrm{g}}$, is equal to:

$$
T=\mathrm{m}_{\Delta \mathrm{g}} / 0,3086 \mathrm{~V} \text {. }
$$

Table 2. The period of time for which the changes in heights due to geodynamic processes do not exceed the errors of their definition (digital mapping technology).

\begin{tabular}{|c|c|c|c|}
\hline \multirow{2}{*}{$\begin{array}{c}\text { Topographic } \\
\text { map scales }\end{array}$} & $\begin{array}{c}\text { Height of } \\
\text { contour interval, } \\
\text { m }\end{array}$ & \multicolumn{2}{|c|}{$\begin{array}{c}\text { Time period } \boldsymbol{T} \text { (year) with speed of vertical } \\
\text { movements } \boldsymbol{V}\end{array}$} \\
\cline { 3 - 4 } & 100 & $\boldsymbol{V}=\mathbf{0 . 1} \mathbf{~ m m} /$ year & $\boldsymbol{V}=\mathbf{0 . 0 1} \mathbf{~ m m} / \mathbf{y e a r}$ \\
\hline $1: 1000000$ & 50 & 20833 & 208333 \\
\hline $1: 500000$ & 20 & 10417 & 104167 \\
\hline $1: 100000$ & 10 & 4167 & 41667 \\
\hline $1: 50000$ & 5 & 2083 & 20833 \\
\hline $1: 25000$ & 2.5 & 1042 & 10417 \\
\hline $1: 10000$ & 2 & 521 & 5208 \\
\hline $1: 5000$ & 1 & 417 & 4167 \\
\hline $1: 2000$ & 0.5 & 208 & 2083 \\
\hline $1: 1000$ & 0.25 & 104 & 1042 \\
\hline $1: 500$ & & 52 & 521 \\
\hline
\end{tabular}

In general, according to the completed research results (Tables 1, 2, 3, and 4), the following conclusions can be drawn:

1. Cartographic materials have significant information for the study of geodynamic processes.

2. Based on the interpretation of information obtained from topographic or gravimetric maps, it is impossible to estimate the stress fields (deformations) of the rock mass of deposits in the modern period 25-50 years, which indicates the need for instrumental recording of modern movements of the crustal blocks in the newest period. 
Table 3. The period of time for which changes in gravity anomalies due to geodynamic processes do not exceed the total errors of their definition (traditional paper technology).

\begin{tabular}{|c|c|c|c|c|}
\hline \multirow{2}{*}{$\begin{array}{l}\text { Gravity map } \\
\text { scales }\end{array}$} & \multirow{2}{*}{$\begin{array}{l}\text { Contour } \\
\text { interval, } \\
10^{-5} \mathrm{~ms}^{-2}\end{array}$} & \multirow[b]{2}{*}{$\begin{array}{c}m_{\Delta g \cdot} \\
10^{-5} \mathrm{~ms}^{-2}\end{array}$} & \multicolumn{2}{|c|}{$\begin{array}{c}\text { Time period } T \text { (year) with speed of } \\
\text { vertical movements } V\end{array}$} \\
\hline & & & $V=0.1 \mathrm{~mm} /$ year & $\begin{array}{c}V=0.01 \\
\text { mm/year }\end{array}$ \\
\hline $1: 1000000$ & 5 & 2 & 64808 & 648088 \\
\hline $1: 500000$ & 5 & 2 & 64808 & 648088 \\
\hline $1: 200000$ & 2 & 1 & 32404 & 324044 \\
\hline $1: 100000$ & 1 & 0.5 & 16202 & 162022 \\
\hline $1: 50000$ & 0.5 & 0.35 & 11341 & 113415 \\
\hline $1: 25000$ & 0.25 & 0.20 & 6480 & 64809 \\
\hline $1: 10000$ & 0,2 & 0.15 & 4860 & 48607 \\
\hline $1: 5000$ & 0.1 & 0.07 & 2268 & 22683 \\
\hline
\end{tabular}

Table 4. The period of time for which changes in gravity anomalies due to geodynamic processes do not exceed the total errors of their definition (digital mapping technology).

\begin{tabular}{|c|c|c|c|c|}
\hline \multirow{2}{*}{$\begin{array}{c}\text { Gravity map } \\
\text { scales }\end{array}$} & \multirow{2}{*}{$\begin{array}{c}\text { Contour } \\
\text { interval, } \\
\mathbf{1 0}^{-5} \mathbf{~ m s}^{-2}\end{array}$} & \multirow{2}{*}{$\mathbf{m}_{\Delta \boldsymbol{g} .}$} & \multicolumn{2}{|c|}{$\begin{array}{c}\text { Time period } \boldsymbol{T} \text { (year) with speed of } \\
\text { vertical movements } \boldsymbol{V}\end{array}$} \\
\cline { 4 - 5 } & & 2 & $\boldsymbol{V}=\mathbf{0 . 1} \mathbf{~ m m} / \mathbf{y e a r}$ & $\begin{array}{c}\boldsymbol{V}=\mathbf{0 . 0 1} \\
\text { mm/year }\end{array}$ \\
\hline $1: 1000000$ & 5 & 2 & 13502 & 135018 \\
\hline $1: 500000$ & 5 & 1 & 13502 & 135018 \\
\hline $1: 200000$ & 2 & 6751 & 67509 \\
\hline $1: 100000$ & 1 & 0.5 & 3375 & 33754 \\
\hline $1: 50000$ & 0.5 & 0.35 & 2363 & 23628 \\
\hline $1: 25000$ & 0.25 & 0.20 & 1350 & 13502 \\
\hline $1: 10000$ & 0.2 & 0.15 & 1013 & 10126 \\
\hline $1: 5000$ & 0.1 & 0.07 & 473 & 4726 \\
\hline
\end{tabular}

\section{Results and discussion}

The relief analysis on remote sensing materials, including UAV technology, is of great importance, since it is an indicator of geological structures [9]. Indicators of the crustal structures on remote sensing materials are lineaments, their study is given serious attention to the study of geodynamic processes. The basis of the use of such geo-indicators as indicators of geodynamic processes is the reflection of mechanical movements of the earth's crust in the landscape. Thus, the analysis of lineaments identified from remote sensing materials is widely used both to study the location and ranking of the structures of the earth's crust $[9,16]$.

The author applied a systematic approach in the development of the theory of digital cartographic support for geodynamic safety based on UAV technologies in areas of development of coal deposits, which includes:

- use of computer technology to highlight lineaments;

- integration of materials for the interpretation of the block structure of the earth's crust;

- improvement of the criteria for the allocation of the crustal blocks;

- facilitation of the identification of the crustal blocks by a visual method;

- unambiguous numbering of the crustal blocks.

Computer processing of relief allows to allocate lineaments and lineament zones. Computer Engineering Center of Kemerovo State University is equipped with software 
packages: PhotoScan, Pix4D, QGIS. At the same time, three-dimensional relief models provide a visual representation of the historical relationship of its forms, and comprehensive data are the source of new information. According to the authors, the most effective combination with geophysical materials. Gravimetric information allows you to confidently identify the crustal blocks and the faults that separate them. Usually, maps of gravitational anomalies and magnetic fields are used in complex geodynamic zoning. Qualitative signs of faults in the anomalous gravitational and magnetic fields are:

- linear stage and violations of the contours;

- variability of signs of anomalies and their drawings. gravity steps.

Analysis of thermal images allows us to study the fields of the earth's infrared radiation flux in fault zones [9]. Allocation of blocks of earth's crust based on morphostructural analysis of cartographic materials includes, first of all, determining the maximum heights of watersheds, tectonic ledges, and flat areas. To distinguish blocks of the earth's crust, qualitative features of relief elements are used: straightened sections of river valleys (Fig. 1), chains of lakes and swamps, passes, foothills [16].

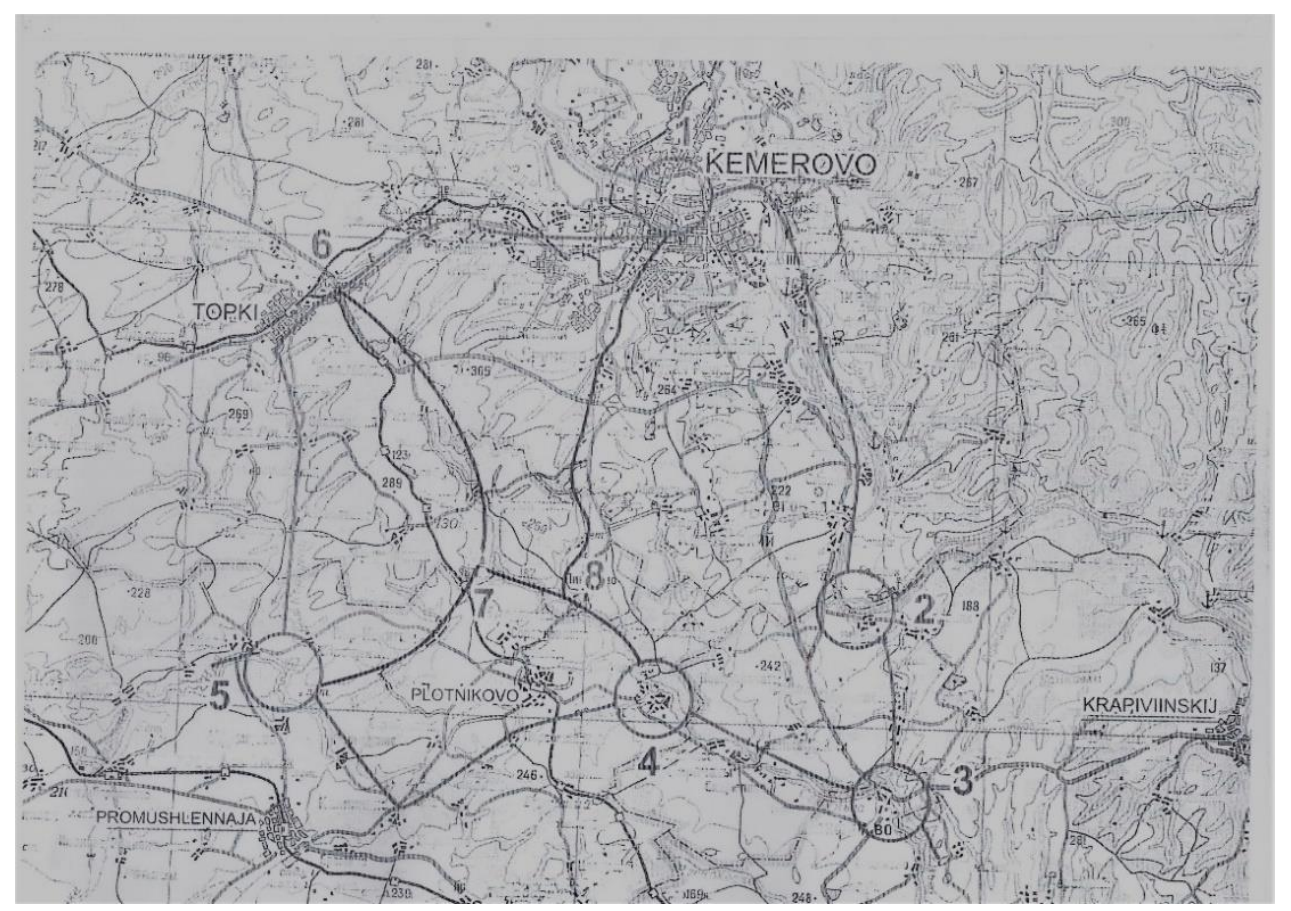

Figure 1. Blocks of earth's crust III-rd and IV-th grades in the area of Kemerovo: 1, 2, 3, 4, 5- the fault intersections of the III grade; 6, 7,8- the fault intersections IV-of his rank; ---- faults bounding the crustal blocks of the III-rd and IV-th grade.

Figure 1 shows a fragment of the allocation of blocks of the earth's crust of the III-th and IV-th ranks on the territory of Kuzbass, and table 5 shows the main characteristics of the faults that limit them. The dominant feature of the allocation of blocks of the earth's crust in figure 1 is the straightened riverbeds, that is, hydrography, due to the formation of modern terrain. 
Table 5. Main characteristics of faults that delimit blocks of the earth's crust.

\begin{tabular}{|c|c|c|l|}
\hline No & Fault & $\begin{array}{c}\text { Length of the fault } \\
\text { section, } \mathbf{k m}\end{array}$ & \multicolumn{1}{|c|}{ The basis of allocation of fault } \\
\hline 1 & $1-2$ & 80 & \multicolumn{1}{c|}{ Along the river Tom } \\
\hline 2 & $2-3$ & 15 & $\begin{array}{l}\text { On the straightened channel of the Unga } \\
\text { River }\end{array}$ \\
\hline 3 & $3-4$ & 30 & $\begin{array}{l}\text { Along the straightened channel of the South } \\
\text { Unga River }\end{array}$ \\
\hline 4 & $4-5$ & 50 & $\begin{array}{l}\text { On the straightened channels of the rivers } \\
\text { South Unga and Kamenka }\end{array}$ \\
\hline 5 & $5-1$ & 70 & $\begin{array}{l}\text { Along the straightened channels of the } \\
\text { Malaya Topki and Bolshoy Korchugan } \\
\text { rivers }\end{array}$ \\
\hline 6 & $6-7$ & 25 & $\begin{array}{l}\text { On the straightened channels of the rivers } \\
\text { North Unga and Mazurovka }\end{array}$ \\
\hline 7 & $7-5$ & 20 & $\begin{array}{l}\text { On the straightened channel of the Iskitim } \\
\text { River }\end{array}$ \\
\hline 8 & $1-8$ & 40 & $\begin{array}{l}\text { Along the straightened channels of the } \\
\text { Talovka and Pryamaya rivers }\end{array}$ \\
\hline 9 & $7-8$ & 7 & $\begin{array}{l}\text { On the straightened channel of the North } \\
\text { Unga River }\end{array}$ \\
\hline 10 & $8-4$ & 10 & $\begin{array}{l}\text { On the straightened channel of the North } \\
\text { Unga River }\end{array}$ \\
\hline
\end{tabular}

According to the methodology of geodynamic zoning, the adjacent areas of the study area belong to different blocks, if the difference in their heights exceeds $\Delta H_{0}\left(\Delta H_{0}-\right.$ minimum height difference) $[9,16]$. The choice of $H_{0}$ is equivocal [16]. The author proposes the extremely minimum value $\Delta \mathrm{H}_{0}$ (Table 6) to accept at least triple the error in determining the heights on the maps, namely:

$$
\Delta H_{0} \geq 3 m_{h}
$$

The extreme minimum value $\Delta \mathrm{H} 0$ characterizes the extreme variant, from the standpoint of structural reading of the earth's surface relief, the more optimal criterion is the condition

$$
\Delta H_{0} \geq 2 h,
$$

where $h$ - height of contour interval.

Identification (setting boundaries on the ground) of blocks of the earth's crust, which consists in determining their position on the ground, is carried out by two methods [16]:

- visually;

- instrumentally.

Table 6. The minimum height difference of the succeeding scales of maps. 


\begin{tabular}{|c|c|c|c|}
\hline $\begin{array}{c}\text { Topographic map } \\
\text { scales }\end{array}$ & $\begin{array}{c}\text { Extreme minimum } \\
\text { height difference } \Delta H_{0}, \\
\mathrm{~m} \\
\text { (traditional paper } \\
\text { mapping technology) }\end{array}$ & $\begin{array}{c}\text { Extreme minimum } \\
\text { height difference } \Delta H_{0}, \\
\mathrm{~m} \\
\text { (digital mapping } \\
\text { technology) }\end{array}$ & $\begin{array}{c}\text { Optimal height } \\
\text { difference, } \mathrm{m}\end{array}$ \\
\hline $1: 1000000$ & 100 & 20,8 & 200 \\
\hline $1: 500000$ & 50 & 10,4 & 100 \\
\hline $1: 100000$ & 20 & 4,2 & 40 \\
\hline $1: 50000$ & 10 & 2,1 & 20 \\
\hline $1: 25000$ & 5 & 1 & 5 \\
\hline $1: 10000$ & 2.5 & 0.5 & 4 \\
\hline $1: 5000$ & 2 & 0.4 & 2 \\
\hline $1: 2000$ & 1 & 0.2 & 10 \\
\hline $1: 1000$ & 0.5 & 0.10 & 0.5 \\
\hline $1: 500$ & 0.25 & 0.05 & \\
\hline
\end{tabular}

Detailed materials of remote sensing (on a scale of 1: 500 - 1: 10 000), especially those obtained with the help of UAV-technologies, greatly facilitate this process, since the monitoring of geodynamic processes is local; the main studied crustal blocks are V and VI ranks, the size of which is no more than ten kilometers.

To implement the modern approach of ensuring unambiguity of information on the selected crustal blocks, based on the use of information technology, the authors propose the following classifier, which includes the region code, year and method of conducting, as well as the hierarchy of the earth's crust. The proposed unique crustal block number includes the following:

- regional code;

- year;

- method of conducting (geological-01; geophysical-02; geomorphological-03; cartographic-04; remote sensing -05; complex-06);

- rank;

- hierarchical number.

The region code defines the subject of the Russian Federation according to the administrative and political division. The rank of the block is determined by the accepted hierarchy of the structure of the earth's crust, so a six-rank system is used for geodynamic zoning of Kuzbass, so the hierarchical number will be a 22-digit number. The investigated block of the earth's crust of the III-th rank, which has the number 42:2019:03:03:000000000305, it is divided into four blocks of the IV-th rank: 42:2019:03:04:305300000305, 42:2019:03: 04:305300000281, 42:2019:03: 04: 305300000258 and 42:2019:03:04:305300000289.

\section{Conclusions}

Based on the performed studies, the following conclusions were made:

1. It is established that the methodological basis of geodynamic safety is the hypothesis of the action of stresses of the latest period, the studied period of relaxation of which reaches one million years. Its information is based on local monitoring for the implementation of which is necessary to perform morphological analysis of the territory.

2. The high information content of cartographic materials for performing morphostructural analysis of the territory and the advantage of its digital representation (especially based on UAV technologies) have been established. The dependences of the periods of relaxation of geodynamic processes on the accuracy of cartographic information obtained on the basis of paper and digital technology are obtained. 
3. The theory of digital cartographic support of geodynamic safety based on UAV technologies is based on computer technology, combining geophysical and topographic materials to interpret the block structure of the earth's crust, improving selection criteria and identification methods, and uniqueness of numbering for use in information technology.

\section{References}

1. $\quad$ Li Feng, Remote Sensing Letters 9.1, 71-80 (2018)

2. K. Gallagher, P. Lawrence, Urban Sustainability: Policy and Praxis (Springer International Publishing, 2016)

3. D.R. Fuka, A.S. Collick, P.J.A. Kleinman, D. Auerbach, D. Harmel, Z.M. Easton, Hydrological Processes 30(24), 4633-4643 (2016)

4. F. Mancini and others, Remote Sensing 5(12), 6880-6898. (2013)

5. A. Arshad, F. Shahab, American Journ. of Geographic Information System 1.2, 17-28 (2012)

6. Zeng Qiang, Natural Hazards 78.2, 957-971 (2015)

7. R.M. Clowes, Canadian Journal of Earth Sciences 47.4, 291-314 (2009)

8. Shin Tao, I.M. Batugina, Geodynamic zoning of residential areas (Beijing, 2010)

9. G.S Melikhova, D.V. Zhirov, V.N. Perein, New structural engineering survey method for design and opetation of deep open pit mines, World finance review (Finetime Ltd., London, 2012)

10. J. Wesseloo, T.R. Stacey, Proceedings In-situ Rock Stress, Balkema 40, 467-471 (2006)

11. C.A. Kreemer, G. Blewitt, E.C. Klein, Geochem, Geophys. Geosyst. 15.10, 3849-3889 (2014)

12. R.G. Gordon, D.F. Argus, Geophys. J. Int. 181, 1-80 (2010)

13. K. Wang, L. Dou, Y. Pan, V.N. Oparin, Journal of Advanced Oxidation Technologies 21(2), 95-110 (2018)

14. A.V. Zhabko, Proceedings XV International ISM Congress 2013 (Aachen, Germany, 2013)

15. V. Perhin, A. Solovitskiy, The Second International Innovative Mining Symposium (2017) http://doi.org/10.1051/e3sconf/ 20172101009 